Rev. Bras. Saúde Prod. Anim., Salvador, v.13, n.1, p.150-159 jan/mar, 2012 http://www.rbspa.ufba.br ISSN 15199940

\title{
Milheto na alimentação de codornas japonesas
}

\author{
Pearl millet in the diet of Japanese quails
}

\author{
GARCIA, Ana Flávia Quiles Marques ${ }^{1 *}$; MURAKAMI, Alice Eiko ${ }^{1}$; MASSUDA, Ely \\ Mitie $^{1}$; URGNANI, Fernando José ${ }^{1}$; POTENÇA, Alexandra ${ }^{1}$; DUARTE, Cristiane \\ Regina do Amaral ${ }^{1}$; EYNG, Cinthia ${ }^{1}$
}

'Universidade Estadual de Maringá, Departamento de Zootecnia, Maringá, Paraná, Brasil.

*Endereço para correspondência: flaviaquiles@gmail.com

RESUMO

Dois experimentos foram conduzidos com o objetivo de determinar o valor energético e o efeito do uso do milheto como fonte energética em rações para codornas japonesas sobre o desempenho e qualidade dos ovos, bem como realizar uma avaliação econômica para verificar a viabilidade da utilização de milheto. No Experimento 1 foram utilizados 72 codornas de postura em um delineamento inteiramente casualizado com dois tratamentos, seis repetições de seis aves cada unidade experimental. A energia do milheto foi de $4142,15 \mathrm{kcal} / \mathrm{EB}$ na MS (\%), 3770,12kcal EMAn na MS(\%)e o teor de PB de $12,58 \%$. No Experimento 2 foram utilizados 336 codornas de postura, distribuídas em um delineamento inteiramente casualizado com seis tratamentos, sete repetições e oito aves cada. Os tratamentos consistiram de seis níveis de substituição do milho pelo milheto, com variação de 0 a $100 \%$. Houve efeito sobre o consumo de ração, o qual aumentou em relação ao controle em todos os níveis utilizados e sobre a conversão alimentar nos níveis de 80 e $100 \%$. Para o índice de coloração de gema houve redução linear à medida que o nível de milheto aumentou nas rações. Para codornas, o milho pode ser substituído pelo milheto em nível de até $100 \%$, sem prejuízos para a produção de ovos (\%) e qualidade dos ovos, exceto para a coloração da gema. O nível de $40 \%$ de inclusão de milheto apresentou a melhor viabilidade econômica e a inclusão de pigmentantes deve ser considerada.

Palavra-chave: alimento alternativo, pigmentantes, nutrição animal, viabilidade econômica

\section{SUMMARY}

Two experiments were carried out to determine the energy value of the pearl millet, and the effects of its use, as energetic source, in the diets of Japanese quails on the performance and eggs quality, as well as to accomplish an economic evaluation in order to verify the viability of using the pearl millet. Experiment 1 was conducted by using 72 japanese quails distributed in metabolism cages. A completely randomized experimental design was conducted, with two treatments, six replicates and nine birds per experimental unit. The crude energy of pearl millet were $4142,15 \mathrm{kcal} / \mathrm{kg}$ (as dry matter) and the apparent metabolizable energy $3770,12 \mathrm{kcal} / \mathrm{kg}$ (as dry matter ) and $12.58 \%$ crude protein. Experiment 2 utilized 336 japaneses quails distributed in a completely randomized experimental design, with six treatments, seven replicates and eight birds per unit. The treatments consisted in diets with different levels of pearl millet (0 to 100\%). There was a significant effect on feed intake witch increased with the levels and for feed conversion in the levels 80 and $100 \%$. The yolk pigmentation index a decreased by increasing of pearl millet. Corn can be replaced by pearl millet for $100 \%$ without compromising the egg production (\%) and egg quality, except the yolk pigmentation. The greater economic viability was calculated at $40 \%$ of inclusion of pearl millet. However, it must be considered the necessity of pigments inclusion.

Keywords: animal nutrition, egg quality, performance, pigments 


\section{INTRODUÇ̃̃̃O}

A produção de codornas japonesas é um segmento que está em crescimento no Brasil, pois é uma cultura de rápido ciclo de produção e elevada eficiência produtiva devido a maturidade sexual precoce, alta taxa de postura e elevada vida produtiva (COSTA et al., 2007). Além disso, existem poucas informações sobre as exigências nutricionais desses animais, o que pode comprometer os custos com alimentação ao subestimar ou superestimar suas exigências, e deste modo causar prejuízos para o setor. Assim, é de grande importância conhecer o metabolismo e as exigências desses animais a fim de proporcionar uma nutrição de precisão, o que promoverá melhorias no desempenho.

A utilização de ingredientes alternativos ao milho nas rações, além de reduzir custos na produção de ovos, é uma oportunidade de encontrar outras fontes energéticas que substituam o milho sem ocorrer prejuízos no desempenho animal, visto que estes representam aproximadamente 65 a $70 \%$ dos custos de produção (RIBEIRO et al., 2003).

$\mathrm{O}$ milheto constitui uma opção como fonte energética para ser utilizado na alimentação animal. Esta fonte possui teores de proteína superiores aos níveis encontrados no milho e apresenta maior concentração de aminoácidos (ADEOLA \& ORBAM, 1995), não possui fatores antinutricionais e é altamente resistente a fungos que podem causar micotoxinas (BANDYOPADHYAY et al., 2007), o que permite a formulação de dietas com menor nível de aminoácidos sintéticos, a fim de reduzir os custos com a ração (MURAKAMI et al., 2009). Por outro lado, o milheto é uma alternativa na alimentação animal por apresentar alta produtividade, precocidade, produtividade e adaptar-se às regiões semiáridas e períodos secos devido à grande rusticidade (BUSO et al., 2011).

Para a formulação de rações para codornas, na maioria dos casos são utilizados valores de energia metabolizável utilizados para frangos de corte e poedeiras, o que muitas vezes não é o correto, visto que esses animais possuem fisiologia metabólica diferente.

Diante do exposto, objetivou-se com este experimento determinar $\mathrm{o}$ valor energético e o efeito do uso do milheto como fonte energética em rações para codornas japonesas sobre o desempenho e qualidade dos ovos, bem como realizar uma avaliação econômica a fim de verificar a viabilidade da utilização de milheto.

\section{MATERIAL E MÉTODOS}

Dois experimentos foram conduzidos no Setor de Coturnicultura da Fazenda Experimental da Universidade Estadual de Maringá. O primeiro foi um ensaio de digestibilidade e o segundo para avaliar o desempenho e qualidade dos ovos. No primeiro experimento foram utilizadas 72 codornas japonesas machos, alojadas em baterias de gaiolas de arame galvanizado, em galpão de postura, com telas nas laterais e coberto com telhas de barro.

$\mathrm{O}$ delineamento experimental utilizado foi inteiramente casualizado, com dois tratamentos (ração referência e ração referência + milheto pérola ADR 7010) e seis repetições, com seis codornas por unidade experimental.

O milheto foi moído e utilizado em substituição parcial de 40\% (matéria natural) à ração referência (RR), à base de milho moído e farelo de soja (45\%). A dieta experimental (Tabela1) foi formulada conforme a composição dos 
alimentos e as exigências preconizados por Rostagno et al. (2005).

O período experimental foi de 10 dias (cinco dias de adaptação + cinco dias de coleta total de excretas), e nesse período as aves receberam ração e água à vontade. As rações foram pesadas no início e no final do período total de coleta de excretas para se obter o consumo médio de ração. Foi utilizado o método tradicional de coleta total de excretas mediante o uso do óxido férrico $(2 \%)$ como marcador do início e do final da coleta.

Tabela 1. Composição percentual e calculada da ração referência

\begin{tabular}{|c|c|}
\hline Ingredientes & $\begin{array}{l}\text { Ração } \\
\text { referência }\end{array}$ \\
\hline Milho grão & 62,74 \\
\hline Milheto & 0 \\
\hline Farelo de soja $45 \%$ & 29,34 \\
\hline Óleo de soja & 5,37 \\
\hline Calcário & 0,247 \\
\hline Fosfato bicálcico & 1,32 \\
\hline Sal comum & 0,35 \\
\hline L-Lisina 98\% & 0,168 \\
\hline DL-Metionina 98\% & 0,171 \\
\hline Premix Min-Vit ${ }^{(1)}$ & 0,3 \\
\hline Total & 100,00 \\
\hline \multicolumn{2}{|l|}{ Valores calculados } \\
\hline EM (kcal/kg) & 2.850 \\
\hline $\mathrm{PB}(\%)$ & 19,00 \\
\hline Cálcio (\%) & 2,50 \\
\hline Fósforo disp. (\%) & 0,350 \\
\hline Met + Cis dig. $(\%)$ & 0,70 \\
\hline Lisina dig. (\%) & 1,00 \\
\hline \multicolumn{2}{|c|}{$\begin{array}{l}\text { Premix mineral e vitamínico. Quantidade/kg da } \\
\text { dieta Vit. A, 8.000.000 UI; Vit. D3, 2.200.000 UI } \\
\text { Vit. E, 6200 mg; Vit. K 3, 2000 mg; Vit. B } 1 \\
\text { 2000mg; Vit. B2, } 3000 \mathrm{mg} \text {; Vit. B6, 6000mg; Vit } \\
\text { B12, 10.000mcg; Pantotenato de cálcio (Calcium } \\
\text { panthotenate), 6000 mg; Niacina,(Niacin) 25.000mg; } \\
\text { Ác. Fólico (Folic acid), 400mg; Se, 100mg; Mn, } \\
65.000 \text { mg; Fe,40.000mg; Cu, 10.000mg; Zn, } \\
50.000 \mathrm{mg} \text {; I, 1000mg }\end{array}$} \\
\hline
\end{tabular}

As gaiolas foram forradas com bandejas revestidas com plásticos devidamente identificados, os quais foram removidos a cada coleta (intervalo de 12 horas) para retirada das excretas. O material coletado, após a retirada dos resíduos de pena, ração e de escamação da pele das aves, foi armazenado em congelador até o final do período total de coletas. Posteriormente, as excretas foram descongeladas, homogeneizadas, pesadas e secas em estufa de ventilação forçada por $72 \mathrm{~h}$ a $55^{\circ} \mathrm{C}$. Em seguida, foram moídas e encaminhadas para as análises de matéria seca (MS), energia bruta (EB) e nitrogênio $(\mathrm{N})$. As análises laboratoriais das rações, dos alimentos e das excretas foram realizadas conforme metodologia descrita por Silva \& Queiroz (2002).

Os valores de EB foram determinados por meio de uma bomba calorimétrica adiabática (Parr Instruments Co.). Os valores de energia metabolizável aparente (EMA) e energia metabolizável aparente corrigida para balanço de nitrogênio (EMAn) dos alimentos foram estimados por meio da utilização da equação de Matterson et al. (1965).

No segundo experimento foram utilizadas 336 codornas japonesas, com 180 dias de idade, alojadas em gaiolas durante $\mathrm{o}$ período de produção, em galpão de postura com telas nas laterais e coberto com telhas de barro.

O delineamento experimental utilizado foi o inteiramente casualizado com seis tratamentos $(0 ; 20 ; 40 ; 60 ; 80$ e $100 \%$ de substituição ao milho), sete repetições e oito aves por unidade experimental.

As rações experimentais, isonutritivas (Tabela 2), foram formuladas à base de milho, milheto pérola -ADR 7010 e farelo de soja, e considerou-se a composição dos alimentos segundo as recomendações de Rostagno et al. (2005). 
Rev. Bras. Saúde Prod. Anim., Salvador, v.13, n.1, p.150-159 jan/mar, 2012 http://www.rbspa.ufba.br ISSN 15199940

O milheto utilizado possuía valores de $4142,15 \mathrm{kcal}$ Energia bruta/kg e $12,58 \%$ de proteína bruta (PB).

$\mathrm{O}$ experimento foi dividido em quatro períodos experimentais de 21 dias (ciclos de produção). No $21^{\circ}$ dia de cada ciclo de produção foi avaliado o consumo de ração (g/ave/dia) e a conversão alimentar ( $\mathrm{kg}$ de ração/kg de ovos e kg de ração/dúzia de ovos), mediante realização da pesagem das rações no início e ao final de cada ciclo.
Os ovos foram coletados diariamente para determinação da produção de ovos (\% de postura). Nos últimos três dias de cada ciclo foram avaliados o peso médio dos ovos, altura de albúmen, gravidade específica, porcentagem e a espessura da casca. As cascas foram quebradas, lavadas em água corrente, secas em temperatura ambiente por 48 horas e pesadas em balança analítica, para determinação da porcentagem de casca.

Tabela 2. Composição percentual e calculada das rações experimentais de codornas japonesas

\begin{tabular}{lcccccc}
\hline Ingredientes & 0 & $20 \%$ & $40 \%$ & $60 \%$ & $80 \%$ & $100 \%$ \\
\hline Milho grão & 62,74 & 51,2 & 39,67 & 28,13 & 16,59 & 5,05 \\
Milheto & 0 & 12,55 & 25,1 & 37,64 & 50,2 & 62,74 \\
Farelo de soja 45\% & 29,34 & 27,99 & 26,64 & 25,29 & 23,94 & 22,59 \\
Óleo de soja & 5,37 & 5,37 & 5,37 & 5,38 & 5,38 & 5,39 \\
Calcário & 0,25 & 0,55 & 0,85 & 1,15 & 1,45 & 1,75 \\
Fosfato bicálcico & 1,32 & 1,33 & 1,34 & 1,35 & 1,38 & 1,38 \\
Sal comum & 0,35 & 0,35 & 0,35 & 0,35 & 0,35 & 0,35 \\
L-Lisina 98\% & 0,168 & 0,191 & 0,213 & 0,236 & 0,26 & 0,28 \\
DL-Metionina 98\% & 0,171 & 0,172 & 0,173 & 0,174 & 0,176 & 0,18 \\
Premix Min-Vit ${ }^{1}$ & 0,3 & 0,3 & 0,3 & 0,3 & 0,3 & 0,3 \\
\hline Total & 100,00 & 100,00 & 100,00 & 100,00 & 100,00 & 100,00 \\
\hline Valores calculados & \multicolumn{7}{c}{} & & & \\
\hline EM (kcal/kg) & 2.850 & 2.850 & 2.850 & 2.850 & 2.850 & 2.850 \\
PB (\%) & 19,00 & 19,00 & 19,00 & 19,00 & 19,00 & 19,00 \\
Cálcio (\%) & 2,50 & 2,50 & 2,50 & 2,50 & 2,50 & 2,50 \\
Fósforo disp. (\%) & 0,350 & 0,350 & 0,350 & 0,350 & 0,350 & 0,350 \\
Met+Cis dig.(\%) & 0,70 & 0,70 & 0,70 & 0,70 & 0,70 & 0,70 \\
Lisina dig. (\%) & 1,00 & 1,00 & 1,00 & 1,00 & 1,00 & 1,00 \\
\hline
\end{tabular}

${ }^{1}$ Premix mineral e vitamínico. Quantidade/kg da dieta Vit. A, 8.000.000 UI; Vit. D3, 2.200.000 UI; Vit. E, 6200mg; Vit. K 3, 2000mg; Vit. B 1, 2000mg; Vit. B2, 3000mg; Vit. B6, 6000mg; Vit. B12, $10.000 \mathrm{mcg}$; Pantotenato de cálcio (Calcium panthotenate), 6000mg; Niacina,(Niacin) $25.000 \mathrm{mg}$; Ác. Fólico (Folic acid), 400mg; Se, 100mg; Mn, 65.000mg; Fe,40.000mg; Cu, 10.000mg; Zn, 50.000mg; I, 1000mg

A espessura da casca do ovo foi obtida com auxílio de um micrômetro digital (Mitutoyo $\left.{ }^{\circledR}\right)$. Para este procedimento verificou-se a medida na região central da casca, onde há maior homogeneidade da distribuição dos cristais de carbonato de cálcio, ou seja, as extremidades da casca do ovo apresentam maior espessura em virtude do maior acúmulo desses cristais.

A altura do albúmen foi aferida mediante o uso de um micrômetro digital cujas 
mensurações, em milímetros, foram relacionadas ao peso do ovo, e assim obteve-se a Unidade Haugh, conforme descrito por Brant \& Shrader (1958): $\mathrm{UH}=100 \log \left(\mathrm{H}+7,57-1,7 \mathrm{~W}^{0,37}\right)$, Em que: $\mathrm{H}=$ altura de albúmen $(\mathrm{mm})$; $\mathrm{W}=$ peso do ovo $(\mathrm{g})$.

A gravidade específica foi realizada, por imersão dos ovos em diferentes soluções salinas, com densidades que variaram de 1,$070 ; 1,074 ; 1,078 ; 1,082$ e $1,086 \mathrm{~g} / \mathrm{mL}$. As soluções salinas foram ajustadas com a utilização de um densímetro de petróleo e derivadas líquidas, calibradas periodicamente.

O índice de coloração da gema foi avaliado com a utilização de um colorímetro da marca Roche, com escala de 1 a 15.

A análise econômica do experimento consistiu na avaliação da Receita Bruta Média, Custo Médio, Margem Bruta e Índice de Rentabilidade da utilização de milheto na alimentação de codornas japonesas.

A Receita Média Bruta é o resultado entre o preço de venda no mercado multiplicado pela quantidade do produto vendido. $\mathrm{O}$ preço dos ovos no atacado foi utilizado como referência (GRANJA FUJIKURA, 2011). Quanto aos ingredientes da ração, estes foram baseados na planilha de preços dos ingredientes do experimento.

O Custo Médio da Ração (CMR) foi calculado conforme a composição centesimal das rações experimentais para uma dúzia de ovos e os preços dos ingredientes. A Margem Bruta (MB) foi obtida pela a diferença entre a Receita Bruta Média (RBM) e o CMR. O Índice de Rentabilidade (IR) foi obtido pelo quociente $\mathrm{MB}$ e CMR, o que mostra a taxa de retorno do capital empregado somente ao se considerar os custos com a ração. $\mathrm{Na}$ análise, este índice indica o retorno obtido com cada real despendido com a ração.
O ponto de equilíbrio indica quantas dúzias de ovos são necessárias para se cobrir os custos com a ração. Ao se considerar que a RBM é produto entre a quantidade de dúzias de ovos produzida (Qdz) e o preço da dúzia de ovos (Pdz), e que, o CMR é produto entre a quantidade de ração consumida (Qr) e o preço da ração conforme tratamento utilizado (Pr), temos que:

$\mathrm{RBM}=\mathrm{Qdz} . \mathrm{Pdz}$

$\mathrm{CMR}=\mathrm{Qr} . \mathrm{Pr}$

No caso, trata-se de ponto de equilíbrio parcial, pois apresenta o volume de produção necessário para cobrir apenas os custos com alimentação, sem levar em consideração os demais custos.

Logo, o ponto de equilíbrio se estabelece quando:

$\mathrm{RBM}=\mathrm{CMR}$

Qdz. Pdz $=$ Qr. Pr

$\mathrm{Qdz}=(\mathrm{Qr} . \mathrm{Pr}) / \mathrm{Pdz}$

Os graus de liberdade referentes aos níveis de inclusão de milheto foram desdobrados em polinômios ortogonais, mediante utilização do programa estatístico SAEG (UFV, 2005).

Para comparação dos resultados obtidos entre a ração-testemunha com cada um dos níveis de substituição de milheto testados, foi utilizado o teste Dunnett a $5 \%$.

\section{RESULTADOS E DISCUSSÃO}

Os valores de energia do milheto foram de $4142,15 \mathrm{kcal} \mathrm{EB} / \mathrm{kg}, 3770,12 \mathrm{kcal}$ EMAn na matéria seca e o coeficiente de metabolização foi de $77,11 \%$. O valor da proteína bruta do milheto foi de $12,58 \% \mathrm{MS}$. Os valores de energia e de proteína do milheto foram similares aos encontrados por Gomes et al. (2007), que relataram $3581 \mathrm{kcal} \mathrm{EMAn} / \mathrm{kg}$ de MS e 78,04 \% de coeficiente de metabolização, mediante utilização de 
Rev. Bras. Saúde Prod. Anim., Salvador, v.13, n.1, p.150-159 jan/mar, 2012 http://www.rbspa.ufba.br ISSN 15199940

milheto cuja energia bruta era de $3909 \mathrm{kcal} / \mathrm{kg}$.

Como a densidade energética da dieta de codornas regula o consumo de ração e pode interferir diretamente no desempenho das aves (SILVA et al., 2003), é de extrema importância a determinação de valores energéticos dos alimentos para codornas.

O consumo de ração apresentou efeito significativo $(\mathrm{P}<0,05)$, o qual aumentou em relação ao controle em todos os níveis de inclusão (Tabela 3). Já a conversão alimentar por dúzias e massa de ovos, os níveis de 80 e $100 \%$ de inclusão de milheto foram diferentes em relação ao controle. Isto pode ser devido às rações serem isoenergéticas e isoproteícas, além do milheto não possuir fatores antinutricionais e ser muito semelhante ao milho. Entretanto, com o aumento do consumo, ainda que os tratamentos não tenham influenciado a produção de ovos, a conversão alimentar piorou significativamente nos níveis de maior inclusão de milheto.

A qualidade interna e externa dos ovos avaliados não foi afetada $(\mathrm{P}>0,05)$ pelos diferentes níveis de inclusão de milheto (Tabela 4). No entanto, houve redução linear $(\mathrm{P}<0,05)$ para $\mathrm{o}$ índice de pigmentação da gema (Figura 1), à medida que se aumentou a inclusão de milheto nas rações ( $\mathrm{Y}=4,70365$ $\left.0,013944 \mathrm{X} ; \mathrm{R}^{2}=0,85\right)$.

Tabela 3. Desempenho de codornas japonesas alimentadas com milheto

\begin{tabular}{|c|c|c|c|c|}
\hline Milheto (\%) & Consumo (g) & Postura (\%) & $\mathrm{CA}^{1}(\mathrm{~kg} / \mathrm{kg})$ & $\mathrm{CA}(\mathrm{kg} / \mathrm{dz})$ \\
\hline 0 & $19,83 \pm 0,28$ & $71,86 \pm 4,01$ & $2,558 \pm 0,03$ & $0,338 \pm 0,09$ \\
\hline 20 & $23,79 \pm 1,29 *$ & $76,64 \pm 5,24$ & $2,522 \pm 0,09$ & $0,333 \pm 0,18$ \\
\hline 40 & $24,68 \pm 0,70^{*}$ & $83,80 \pm 2,83$ & $2,823 \pm 0,07$ & $0,337 \pm 0,16$ \\
\hline 60 & $23,95 \pm 0,68^{*}$ & $76,89 \pm 2,70$ & $2,568 \pm 0,09 *$ & $0,367 \pm 0,01$ \\
\hline 80 & $24,12 \pm 0,77^{*}$ & $77,65 \pm 2,88$ & $3,391 \pm 0,05^{*}$ & $0,416 \pm 0,01 *$ \\
\hline 100 & $24,12 \pm 0,77^{*}$ & $77,65 \pm 2,88$ & $3,391 \pm 0,05^{*}$ & $0,446 \pm 0,04^{*}$ \\
\hline $\mathrm{CV}(\%)$ & 7,69 & 5,78 & 5,79 & 5,65 \\
\hline Regressão & Ns & Ns & Ns & Ns \\
\hline
\end{tabular}

Tabela 4. Qualidade de ovo de codornas japonesas alimentadas com milheto

\begin{tabular}{lcccccc}
\hline $\begin{array}{c}\text { Milheto } \\
(\%)\end{array}$ & $\begin{array}{c}\text { Peso ovo } \\
(\mathrm{g})\end{array}$ & \% Casca & $\begin{array}{c}\text { Espessura } \\
\text { casca }\end{array}$ & $\begin{array}{c}\text { Unidade } \\
\text { Haugh }\end{array}$ & $\begin{array}{c}\text { Grav. } \\
\text { especifica }\end{array}$ & Gema $^{1}$ \\
\hline 0 & $10,82 \pm 0,20$ & $7,51 \pm 0,11$ & $0,257 \pm 0,002$ & $88,76 \pm 0,41$ & $1,071 \pm 0,0004$ & $4,68 \pm 0,11$ \\
20 & $10,52 \pm 0,18$ & $7,60 \pm 0,05$ & $0,260 \pm 0,004$ & $89,07 \pm 0,40$ & $1,071 \pm 0,0002$ & $4,40 \pm 0,08$ \\
40 & $10,70 \pm 0,15$ & $7,51 \pm 0,07$ & $0,256 \pm 0,003$ & $89,19 \pm 0,29$ & $1,071 \pm 0,0004$ & $4,16 \pm 0,06$ \\
60 & $10,65 \pm 0,15$ & $7,51 \pm 0,06$ & $0,265 \pm 0,005$ & $88,96 \pm 0,28$ & $1,072 \pm 0,0002$ & $4,01 \pm 0,08$ \\
80 & $10,62 \pm 0,16$ & $7,39 \pm 0,03$ & $0,252 \pm 0,002$ & $88,27 \pm 0,21$ & $1,071 \pm 0,0002$ & $3,65 \pm 0,02$ \\
100 & $10,59 \pm 0,13$ & $7,54 \pm 0,13$ & $0,252 \pm 0,001$ & $88,32 \pm 0,53$ & $1,071 \pm 0,0003$ & $3,20 \pm 0,06$ \\
\hline CV $(\%)$ & 4,85 & 1,62 & 5,19 & 1,27 & 0,06 & 4,64 \\
\hline Regressão & $\mathrm{Ns}$ & $\mathrm{Ns}$ & $\mathrm{Ns}$ & $\mathrm{Ns}$ & $\mathrm{Ns}$ & Linear \\
\hline
\end{tabular}

${ }^{1}$ Coloração da gema. *Teste de Dunnett $(\mathrm{P}<0,05)$. 


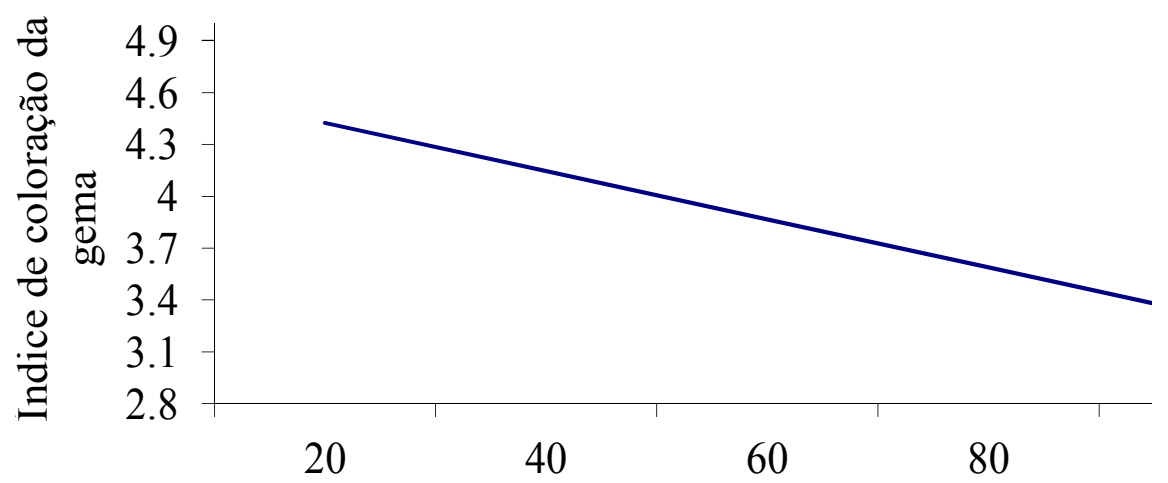

Figura 1. Índice de coloração da gema dos ovos de codornas japonesas alimentadas com rações contendo diferentes níveis de milheto em substituição ao milho ( $\left.\mathrm{Y}=4,70365-0,013944 \mathrm{X}, \mathrm{R}^{2}=0,85\right)$

Resultados semelhantes foram encontrados por Leandro et al. (1999), Garcia et al. (2011), Collins et al. (1997), Café et al. (1999) e Filardi et al. (2005), ao avaliarem o desempenho produtivo e a qualidade de ovos de codornas e poedeiras comerciais, com níveis que variaram de 0 a $100 \%$ de inclusão de milheto em substituição ao milho, observaram que não foram afetados o desempenho e qualidade de ovos, exceto coloração de gema, a qual piorou à medida que os níveis de milheto foram crescentes na ração. Isto está relacionado com a presença de carotenóides existentes em maior quantidade no milho, porém este problema pode ser evitado com o uso de pigmentantes. Entretanto, Mehri et al. (2010) ao utilizarem rações para poedeiras comerciais com níveis de substituição de 0 a $100 \%$ de milho em relação ao milheto, registraram níveis de até $75 \%$ de substituição, sem prejuízos para o desempenho dos animais.

Para Carvalho (2006), os carotenóides na alimentação de poedeiras são responsáveis pela coloração da gema do ovo, e pode esta coloração ser controlada pela dieta. Assim, a concentração de carotenóides presentes no milho também poderá interferir sobre a coloração da gema.

O milheto possui em sua composição uma alta porcentagem de óleo e teores de proteína superiores ao milho, fatores que fazem com que o milheto apresente uma alta energia metabolizável, o que pode ter melhorado o aproveitamento de nutrientes (LAZZARI, 2005). A grande vantagem da utilização do milheto é a ausência de fatores antinutricionais, em comparação a outras culturas utilizadas como fonte energética nas rações em substituição ao milho como, por exemplo, o sorgo.

A Receita Média corresponde ao preço da dúzia de ovos (Tabela 5). O custo da ração reduziu conforme os níveis de adição do milheto devido ao preço do produto em relação ao milho. No entanto, o menor Custo Médio da ração foi apresentado aos $40 \%$ de adição de milheto, o que incide também sobre o comportamento da Margem Bruta. O Índice de Rentabilidade do tratamento $40 \%$ milheto indica que, para cada unidade monetária utilizada para ração há retorno de $101 \%$, o mais elevado entre os tratamentos inferidos. 
Rev. Bras. Saúde Prod. Anim., Salvador, v.13, n.1, p.150-159 jan/mar, 2012 http://www.rbspa.ufba.br ISSN 15199940

Tabela 5. Parâmetros de avaliação econômica para uma caixa de uma dúzia de ovos (Receita Bruta Média (RBM), Custo da Ração (CR), Custo Médio da Ração (CMR), Margem Bruta (MB) e Índice de Rentabilidade (IR), com base no Milho $=100)$

\begin{tabular}{lcccccc}
\hline \multirow{2}{*}{ Item } & \multicolumn{6}{c}{ Nível de adição de Milheto } \\
\cline { 2 - 7 } & $0 \%$ & $20 \%$ & $40 \%$ & $60 \%$ & $80 \%$ & $100 \%$ \\
\hline Receita Bruta Média & 0,540 & 0,540 & 0,540 & 0,540 & 0,540 & 0,540 \\
Custo da Ração/kg & 0,598 & 0,565 & 0,531 & 0,498 & 0,465 & 0,432 \\
Custo Médio da Ração/dúzia & 0,203 & 0,188 & 0,179 & 0,183 & 0,194 & 0,193 \\
Margem Bruta & 0,337 & 0,352 & 0,361 & 0,357 & 0,346 & 0,347 \\
Índice de Rentabilidade & 1,664 & 1,870 & 2,015 & 1,959 & 1,787 & 1,800 \\
\hline
\end{tabular}

Os números índices (Figura 2) indicam o comportamento das diferentes variáveis em relação ao controle e permitem estabelecer comparações entre os tratamentos, já o controle é sempre fixado no valor base de 100. Assim, verifica-se que o Custo de Ração 100\% representa cerca de $72 \%$ da ração testemunha. No entanto, o menor Custo Médio recaiu sobre o tratamento $40 \%$ milheto, que representou $88 \%$ do custo da ração $0 \%$ milheto. Os números índices da Margem Bruta e do Índice de Rentabilidade foram superiores em $6 \%$ e $21 \%$, respectivamente, à ração testemunha.

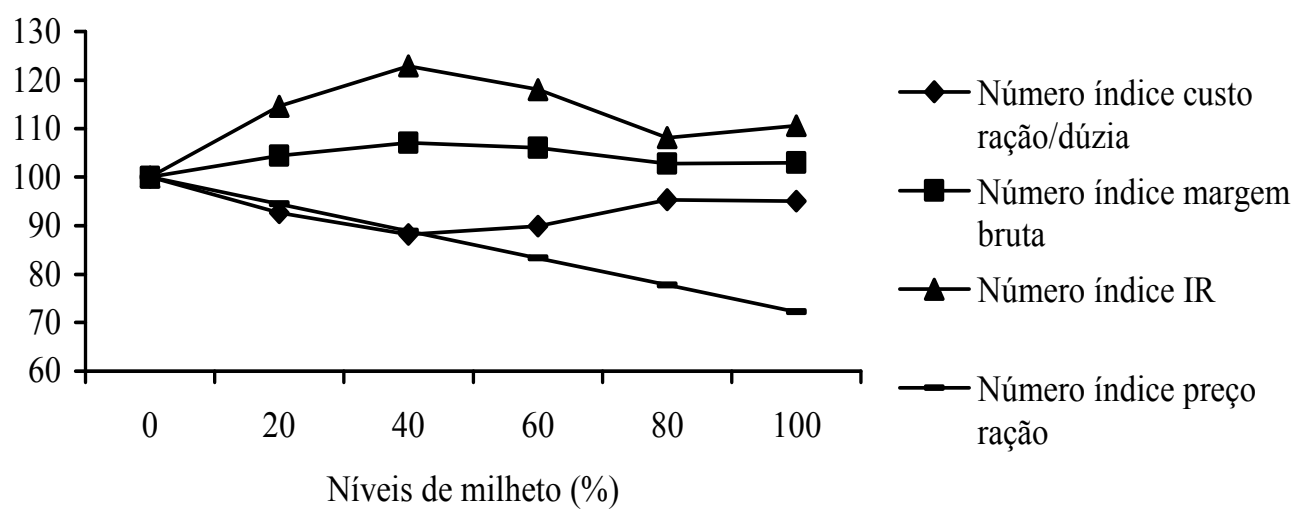

Figura 2. Números Índices do Custo Médio da Ração, da Margem Bruta e do Índice de Rentabilidade, com base no tratamento sem a inclusão de milheto $(0 \%$ adição de milheto $=100)$

O ponto em que o volume de produção que cobre os custos, chamado de ponto de equilíbrio, mostra quantos ovos são necessários para se cobrir os custos com a ração para produção de uma dúzia do produto (Tabela 6). Esta ponto de equilíbrio, teoricamente, indica o momento que define o volume exato de produção que apresente retorno zero. No caso, por se tratar de avaliação do volume de produção requerido para se cobrir o custo da alimentação, tem-se o ponto de equilíbrio parcial, pois não se levam em consideração os demais 
Rev. Bras. Saúde Prod. Anim., Salvador, v.13, n.1, p.150-159 jan/mar, 2012 http://www.rbspa.ufba.br ISSN 15199940

custos, mas especifica o número de ovos necessários para se cobrir os custos com a ração. Ou seja, para o tratamento $40 \%$ milheto, 3,98 ovos cobrem os custo da ração. No enquanto para o tratamento testemunha são precisos 4,5 ovos, o que leva a crer que em escalas produtivas tais números podem ser significativos.

Tabela 6. Ponto de Equilíbrio segundo os Tratamentos

\begin{tabular}{lc}
\hline $\begin{array}{c}\text { Níveis de Milheto } \\
(\%)\end{array}$ & $\begin{array}{c}\text { Ponto de } \\
\text { Equilíbrio }\end{array}$ \\
\hline $0 \%$ & 4,51 \\
$20 \%$ & 4,18 \\
$40 \%$ & 3,99 \\
$60 \%$ & 4,06 \\
$80 \%$ & 4,31 \\
$100 \%$ & 4,29 \\
\hline
\end{tabular}

Nas condições em que o experimento foi conduzido, concluiu-se que o milheto pode substituir o milho em até $100 \%$ na ração, sem prejuízos na produção de ovos e qualidade externa dos ovos de codornas. Além disso, o custo da ração foi reduzido gradualmente com adição de milheto na ração, e a inclusão de $40 \%$ foi a que apresentou melhor índice de rentabilidade.

Contudo, deve-se considerar a necessidade da inclusão de pigmentantes, de acordo com as necessidades do mercado consumidor.

\section{REFERÊNCIAS}

ADEOLA, O.; ORBAN, J.I. Chemical composition and nutrient digestibility of pearl millet (Pennisetum glaucum) fed to growing pigs. Journal of Cereal Science, v.22, p.177-184, 1995.
BANDYOPADHYAY, R.; KUMAR, M.; LESLIE, J. Relative severity of aflatoxin contamination of cereal crops in West Africa. Food Additives and Contaminants: Part A, v.24, n.10, p.1109-1114, 2007.

BRANT, A.W.; SHRADER, H.L.

Equipment and methods for measuring egg quality. Washington: Department of Agriculture, 1958. p.17.

BUSO, W.H.D.; MACHADO, A.S.; SILVA, L.B.; FRANÇA; A.F.S. Uso do milheto na alimentação animal.

PUBVET, v.5, n.22, Art. 1136, 2011.

CAFÉ, M.B.; STRINGHINI, J.H.; MOGYCA, N.S.; FRANÇA, A.F.S.; ROCHA, F.R.T. Milheto-grão (Pennisetum glaucum (L.R.Br.) como substituto do milho em rações para poedeiras comerciais. Revista Brasileira de Zootecnia, v.51, n.2, p. 171-176, 1999.

CARVALHO, P.R.; PITA, M.C.G.; REBER-NETO, E.; MIRANDOLA, R.M.S.; MENDONÇA JÚNIOR, C.X. Influência da adição de fontes marinhas de carotenóides à dieta de galinhas poedeiras na pigmentação da gema do ovo. Brazilian Journal of Veterinary Research and Animal Science, v.43, n.5, p.654-663, 2006.

COLLINS, V.P.; CANTOR, A.H.; PESCATORE, A.J.; ESTRAW, M.L.; FORD, M.J. Pearl millet in layer diets enhances egg yolk n-3 fatty acids.

Poultry Science, v.76, p.326-330, 1997.

COSTA, C.H.R.; BARRETO, S.L.T.; MOURA, W.C.O.; REIS R. S.; LEITE, C.D.S.; MARA, G.V. Níveis de fósforo e cálcio em dietas para codornas japonesas em postura. Revista Brasileira de Zootecnia, v.36, n.6, p.2037-2046, 2007. 
Rev. Bras. Saúde Prod. Anim., Salvador, v.13, n.1, p.150-159 jan/mar, 2012 http://www.rbspa.ufba.br ISSN 15199940

FILARDI, R.S.; JUNQUEIRA, O.M.; CASARTELLI, E.M.; LAURENTIZ, A.C.; DUARTE, K.F.; ASSUENA, V. Pearl millet utilization in commercial laying hen diets formulated on a total or digestible amino acid basis. Brazilian Journal of Poultry Science, v. 7, n.2, p.99-105, 2005.

GARCIA, A.F.Q.M.; MURAKAMI, A.E.; FURLAN, A.C.; MASSUDA, E.M.; POTENÇA, A.; ROJAS, I.C.O. Milheto na alimentação de poedeiras. Acta Scientiarum. Animal Sciences, v.33, p.73-75, 2011.

GOMES, F.A.; FASSANI, E.J.; RODRIGUES, P.B.; SILVA, J.C. Valores energéticos de alguns alimentos utilizados em rações para codornas japonesas.

Revista Brasileira de Zootecnia, v.36, p.396-402, 2007.

GRANJA FUJIMURA. Produtos.

Disponível em:

$<$ www.granjafujimura.com.br $>$. Acesso em: 03 jan. 2011.

LEANDRO, N.S.M.; CAFÉ, M.B.; STRINGHINI, J.H.; FRANÇA, A.F.S.; FREITAS S.A. Milheto (Pennisetum glaucum (L.) R.Br.) como substituto do milho em rações para codornas-japonesas em postura (Coturnix coturnix japonica).

Revista Brasileira de Medicina

Veterinária e Zootecnia, v.51, n.2, p.177181, 1999.

MATTERSON, L.B.; POTTER, L.M.; STUTZ, M.W.; SINGSEN, E P. The metabolizable energy of feed ingredients for chickens. Agricutural Experiment Station University of Connecticut, n.7, p.3-11, 1965.

MEHRI, M.; POURREZA, J.; SADEGHI, G. Replacing maize with pearl millet in laying hens' diets. Tropical Animal

Health and Production, v.42, p.439-444, 2010.
MURAKAMI, A.E.; SOUZA, L.M.G.; MASSUDA, E.M.; ALVES, F.V.; GUERRA, R.L.H.; GARCIA, A.F.Q.M. Avaliação econômica e desempenho de frangos de corte alimentados com diferentes níveis de milheto em substituição ao milho. Acta Scientiarum. Animal Sciences, v.31, p.31-37, 2009.

RIBEIRO, M.L.G.; SILVA, J.H.V.; DANTAS, M.; COSTA, F.G.P.; OLIVEIRA, S.F.; JORDÃO FILHO, J.; SILVA, E.L. Exigências nutricionais de lisina para codornas durante a fase de produção em função do nível de proteína da ração. Revista Brasileira de

Zootecnia, v.32, n.1, p.156-161, 2003.

ROSTAGNO, H.S.; ALBINO, L.F.T.; DONZELE, J.L.; GOMES, P.C.; OLIVEIRA, R.F.; LOPES, D. C.; FERREIRA, A.S.; BARRETO, S.L.T.

Tabelas brasileiras para aves e suínos: composição de alimentos e exigências nutricionais. 2.ed. Viçosa, MG: Universidade Federal de Viçosa, 2005.

SILVA, D.J.; QUEIROZ, A.C. Análise de alimentos: métodos químicos $\mathrm{e}$ biológicos. 3.ed. Viçosa, MG:

Universidade Federal de Minas Gerais, 2002. 235p.

SILVA, J.H.V.; SILVA, M.B.; SILVA, E.L.; JORDÃO FILHO, J.; RIBEIRO, L.G.; COSTA, F.G.P.; DUTRA JÚNIOR, W.M. Energia Metabolizável de Ingredientes Determinada com Codornas Japonesas (Coturnix coturnix japonica). Revista Brasileira de Zootecnia, v. 32, n.6, p.1912-1918, 2003.

UNIVERSIDADE FEDERAL DE VIÇOSA - UFV. SAEG: sistema de análises estatísticas e genéticas. Versão 9.0. Viçosa, MG: Universidade Federal de Viçosa, 2005.

Data de recebimento: 25/05/2011

Data de aprovação: 09/02/2012 